\title{
Binasal hemianopia
}

\author{
J. E. A. O'CONNELl AND E. P. G. H. DU BOULAY
}

From St. Bartholomew's Hospital, London

SUMMARY Three patients with nasal visual field defects are described. In each case it is believed that compression of the lateral fibres of the optic nerve by the anterior cerebral or internal carotid artery was the cause. Binasal hemianopia can thus be produced by a single lesion and is as much a true hemianopia as the common bitemporal one. The value of careful neuroradiological investigation to display the relationships of a tumour to the chiasma, optic nerves, and related vessels and thus explain the field defects is demonstrated.

Isolated loss of the nasal fields of vision is uncommon. In Traquair's Clinical Perimetry (Scott, 1957) it is stated that the term hemianopia is best reserved for bilateral field defects produced by a single lesion-chiasmal or suprachiasmal. This author considered that binasal hemianopia was not a true hemianopia, since its occurrence indicated bilateral involvement of the uncrossed fibres at the chiasma, the crossed fibres remaining intact. This could be due to displacement of the terminal parts of both optic nerves against the internal carotid arteries in internal hydrocephalus: atherosclerosis or aneurysms of both internal carotid vessels could lead to compression of the nerves in the same area: symmetrical gummata or other lesions could produce a similar result. Duke-Elder (1971) also takes the view that bilateral symmetrical lesions at the chiasma are necessary for the development of binasal hemianopia, though he suggests that bilateral occipital lesions might produce such a defect. From a list of possible causes those due to pressure which are mentioned are atherosclerosis or aneurysms of the internal carotid arteries compressing the terminations of both optic nerves, or displacement of the nerves against blood vessels by a local tumour, or a distended third ventricle in internal hydrocephalus. It is hoped to show in this paper that binasal hemianopia can result from a single intracranial lesion and that, though rare, it is therefore as much a true hemianopia as is the common bitemporal one.

Although the importance of ophthalmoscopy and visual field examination began to be recog- nized during the middle of the last century, the passage of time and increasing experience were necessary before these methods of clinical investigation could be fully utilized. During the same period the pathology of compression of the optic nerves and chiasma attracted considerable attention and a number of descriptions of involvement of these structures by the Willisian vessels, observed at postmortem examination, appeared. In 1852 Turck described the necropsy findings in a patient with a pituitary tumour who had total blindness in the left eye with some residual vision in the right one. Both optic nerves were deeply grooved by the anterior cerebral arteries and on the left the optic tract was also grooved; at the site of compression the left optic nerve was reduced to an empty sheaththere being preservation of the medial one-third of the right one. Knapp (1873) had stated that sclerosis of the intracranial internal carotid arteries could cause blindness. Smith (1905) reported his postmortem finding of atrophy of both optic nerves secondary to atherosclerosis of the supraclinoid portion of the internal carotid arteries. He had seen altogether six such cases in dissecting and postmortem rooms in Cairo. He refers to the second edition of Fuchs's Textbook of Ophthalmology published in the United States in 1903 as also describing such cases. In 1905 Sachs, cited by Fay and Grant (1928), described the necropsy findings in 48 cases of pituitary tumour and noted that in two the optic nerves were grooved by the anterior cerebral arteries. Bartels (1906) cited Erdheims's account of seven 
necropsy specimens in which the optic nerves and chiasma were grooved by the anterior cerebral or anterior communicating arteries, or the optic tract by the internal carotid artery. Bartels also described a case of his own in which the tracts were grooved by the anterior cerebral arteries. Uhthoff (1911) described another such case where the anterior cerebral arteries constricted the optic nerves.

Sixty years ago, in a number of papers, Cushing and Walker reported their careful studies of the visual fields in patients with intracranial tumours; among these was one on binasal hemianopia which appeared in 1912. These authors had noted in patients with optic atrophy secondary to high intracranial pressure that, where some vision had been retained, this was usually in the temporal fields. They suggested that the uncrossed fibres at the chiasma were damaged not only at the nerve head by developing scar tissue here, but also close to the chiasma as a result of pressure of the nerves against the internal carotid arteries occasioned by distension of the third ventricle. The visual acuity was so reduced in their patients that it is extremely doubtful if the small islands of temporal vision which persisted justified the diagnosis of binasal hemianopia. Hirsch (1921) described grooving of both optic nerves by both anterior cerebral arteries and of the chiasma by the anterior communicating artery as a necropsy finding in a patient with a pituitary tumour. Fay and Grant (1923) provided a good review of the literature and described a case of interpeduncular craniopharyngioma, which had displaced the chiasma anteriorly so that the optic tracts on both sides were grooved by the internal carotid arteries, the left one also being grooved by the anterior cerebral artery. These authors attributed the nasal portion of the severe visual field disturbance in this patient to vascular notching of the optic tracts. Balado and Malbran (1933a, b) discussed involvement of the optic nerves, tracts, and chiasma by related arteries in the presence of pituitary tumours, cerebral tumours in various situations, and internal hydrocephalus. In addition, they describe three patients with binasal hemianopia and in each case relate this to the postmortem findings. Rucker and Kernohan (1954) described the necropsy findings in five patients who died after surgery for pituitary tumours; excellent photographs demonstrate the grooving of the nervous structures by the vascular ones in these postoperative cases. The relationship of the findings to the field changes is by no means clear and it would seem that postoperative swelling of residual tumour tissue accounted in some measure for the postmortem findings.

It will be seen that all these studies have been based on the examination of postmortem material. With the development of neurological surgery, and resulting accurate diagnosis and successful surgical treatment of tumours in the sellar region, the opportunities for such postmortem examinations dwindled. At the same time the surgeon's goal would be to excise the lesion with minimal trauma and the wide exposure possible at postmortem examination would not be obtained. Perhaps for this reason, relatively little has been said in recent years concerning the involvement of the optic chiasma, nervesp and tracts by related vessels and its possible relationship to the production of visual fiel $\Phi$ defects. It is probable that many surgeons have noticed grooving of the optic nerve or chiasm by the anterior cerebral artery in operating fos pituitary tumours and some have related this t an inferior quadrantic nasal field defect on theे affected side (Schneider et al., 1970).

Modern methods of investigation and their skilful interpretation can provide very full information concerning the relationship of the optic nerves and chiasma, the Willisian vessels, and an associated tumour mass to one another. With the single exception of the bony landmarks of the posterior margin of the optic canal in the lateral skull view, the radiological anatomy is well known. The pneumographic appearance of the chiasmatic cistern was described in detail by Dilenge in 1955 and by Liliequist in 1959. Bull (1955) has made a detailed study of the normal variations in the position of the optic recess of the third ventricle and Gado and Bull have recently (1971) shown the many ways in which the anterior cerebral arteries may be displaced by suprasellar masses.

In the normal patient the pre-communicating parts of the anterior cerebral arteries bear a $\sigma$ fairly constant relationship to the chiasma and $N$ may, of course, be demonstrated by angio- N graphy, but a more precise localization of the 


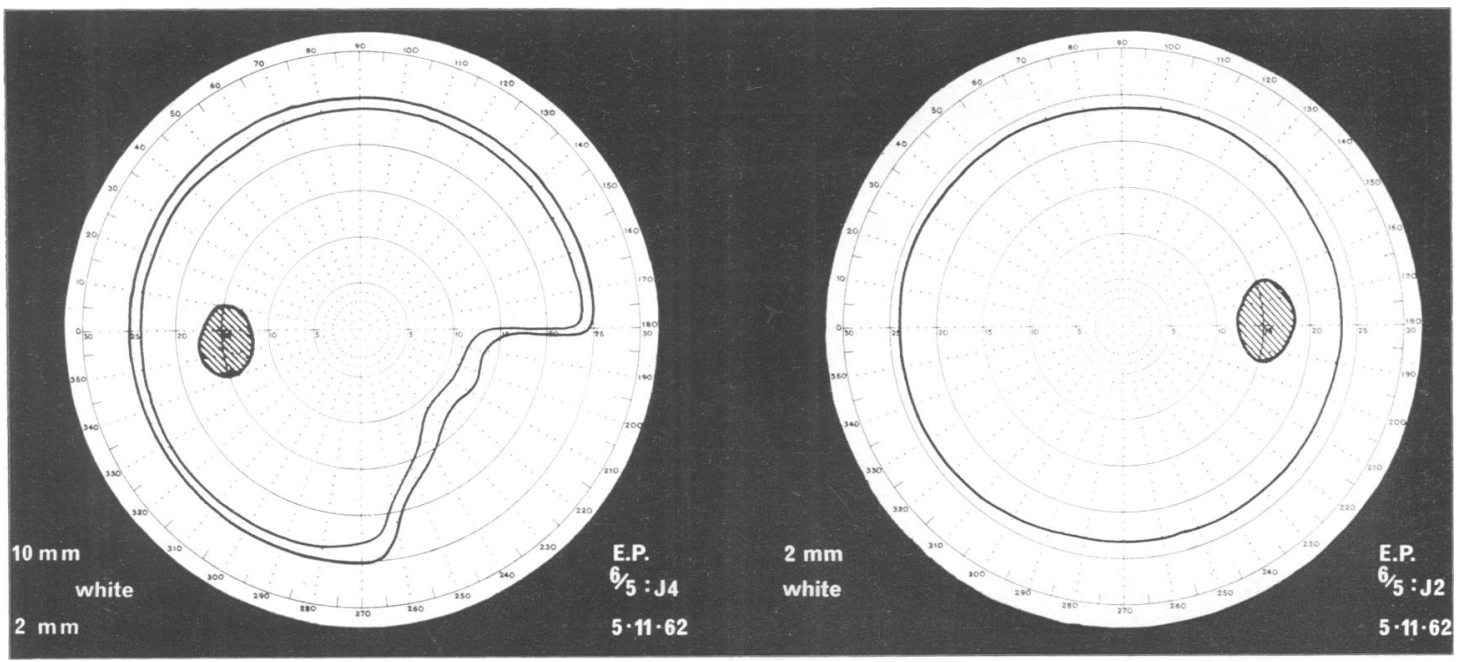

FIG. 1. Case 1. Fields of vision.

optic chiasma and the intracranial parts of the optic nerves is possible both in the normal and the abnormal patient by observation of certain other anatomical features shown during the various radiographic examinations. At both pneumoencephalography and ventriculography the impression made by the optic chiasma on the anterior end of the third ventricle, between the optic and infundibular recesses, may, itself, regularly be seen. This is true, also, in abnormal cases when the chiasma and the third ventricle are displaced. It may be seen in the cases under discussion here and it locates the transverse limb of the optic chiasma for the observer. At pneumoencephalography also, that part of the chiasma which extends forwards as well as the intracranial portions of the optic nerves may be directly outlined by air in the chiasmatic cistern, and may be seen, when normal, without the benefit of tomography in lateral views; but tomography is a valuable addition in confirming the exact limits of the shadows and in distinguishing right from left. In anteroposterior projections tomography is essential in determining the precise positions of the nerves within the normal airfilled chiasmatic cisterns.

When the optic nerves are stretched over the surface of a tumour it becomes impossible to surround them with air so that they, themselves, can only rarely be seen for any considerable part of their course, even after the most careful pneumography in cases of pituitary adenoma. However, just as the attachment of the chiasma to the third ventricle can virtually always be shown even in abnormal cases (by pneumoencephalography), so can the anterior point of attachment of the optic nerves at the skull base be recognized on lateral plain radiographs and this localization may be transferred to lateral angiograms and lateral air studies. Accurately centred, good quality lateral radiographs of the skull show a short, fine, curved line-shadow just anterior to and approximately on a level with the lower border of the anterior clinoid process. This line represents either the posterior, superior, lateral or the posterior, superior, medial margin of the optic canal, depending upon the individual skull. The optic nerve is below it, or in some cases crosses its down-turned curve. The line-shadow has been used in the present cases to fix the point from which the optic nerve emerges into the cranial cavity. In anteroposterior and posteroanterior skull views the position of the optic canal may also be defined even if its details are invisible, chiefly by its relationship to the anterior clinoid process. The ophthalmic artery is almost invariably filled with contrast medium during carotid angiography and may be seen in lateral, Towne's, and other anteroposterior views. It has a recognizable osseous portion. 


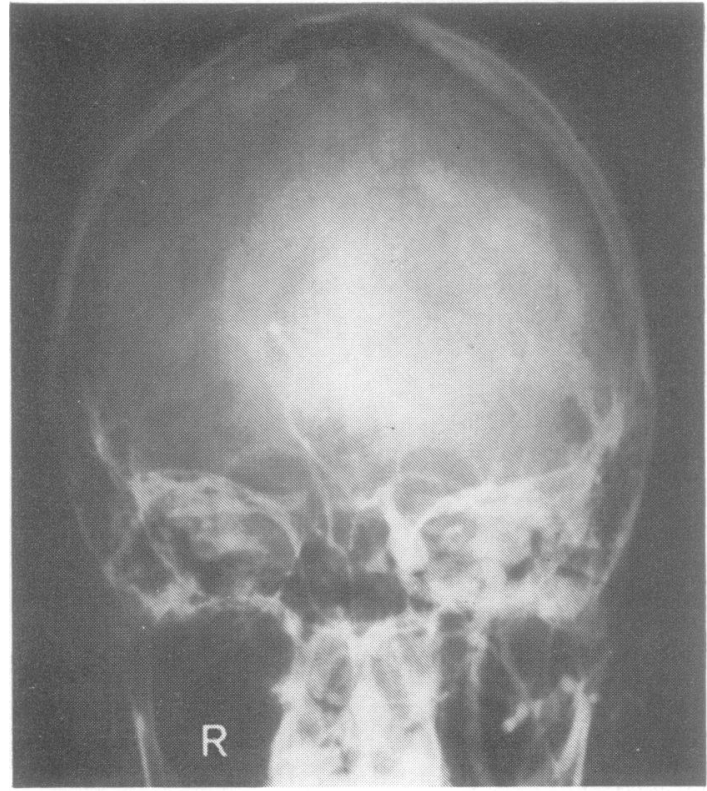

(a)

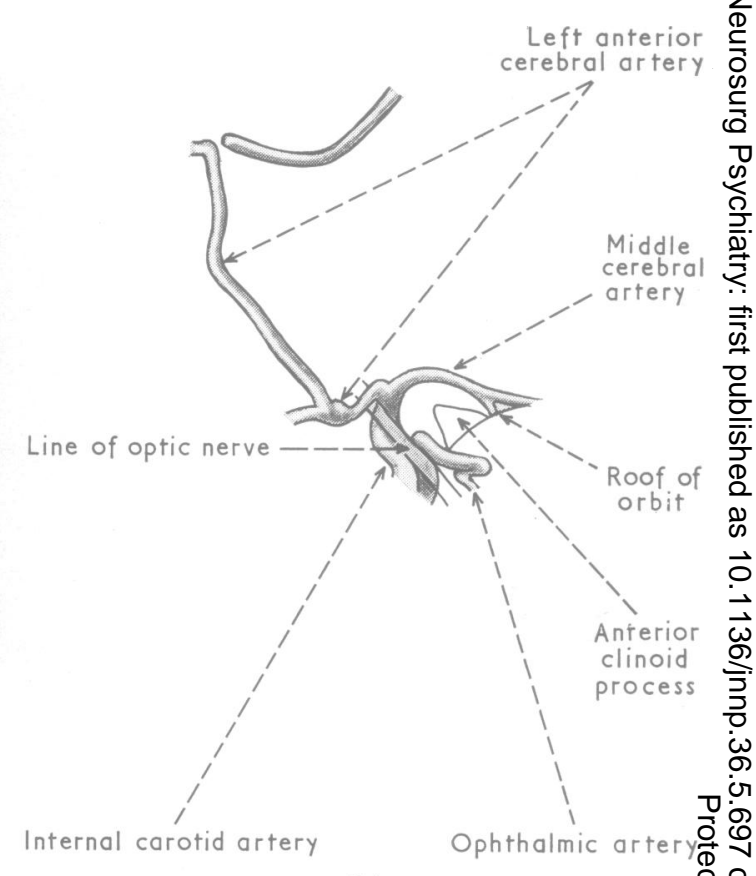

(b)

FIG. 2. Case 1. (a) Left carotid angiograms: A.P. (b) Explanatory drawing showing displacement of le 0 anterior cerebral artery across the line of the left optic nerve.

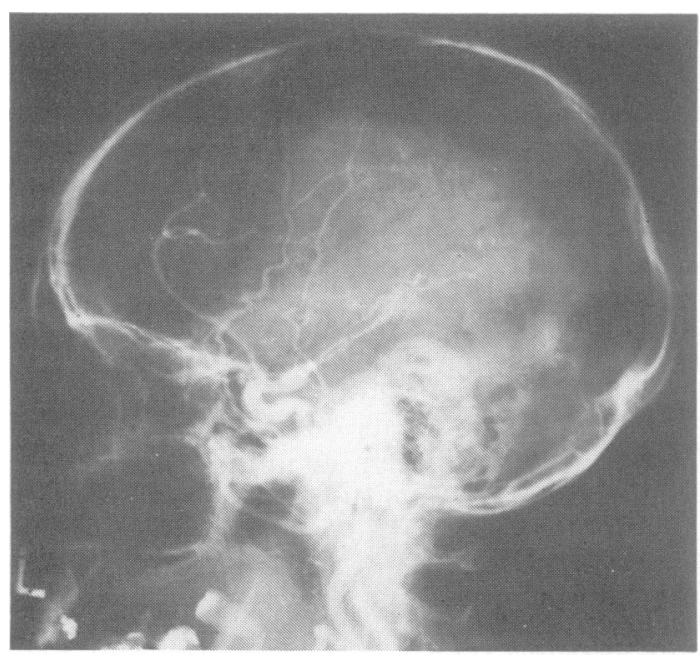

(a)

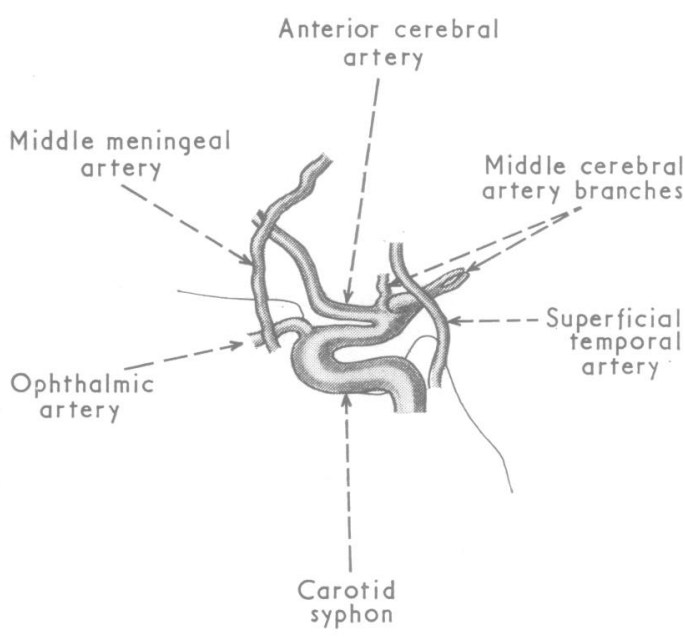

(b)

FIG. 3. Case 1. (a) Left carotid angiogram: lateral. (b) Explanatory drawing: this traces the carotid syphon, $\mathcal{D}_{\mathcal{N}}$ ophthalmic artery, and precommunicating part of the anterior cerebral artery and shows how the line of the optic $\mathbb{\omega}_{\mathrm{N}}$ nerve must be altered by the medial displacement of the inferiorly situated anterior cerebral artery. 
This also serves to fix the situation of the optic nerve in any angiographic projection.

Thus, by a combination of radiographic techniques it is possible either to predict the exact course of, or actually see, the intracranial portions of the optic nerves and the optic chiasma in patients who undergo neuroradiological investigation for tumours in the sellar region. It should be noted that these same methods demonstrate and localize the terminal
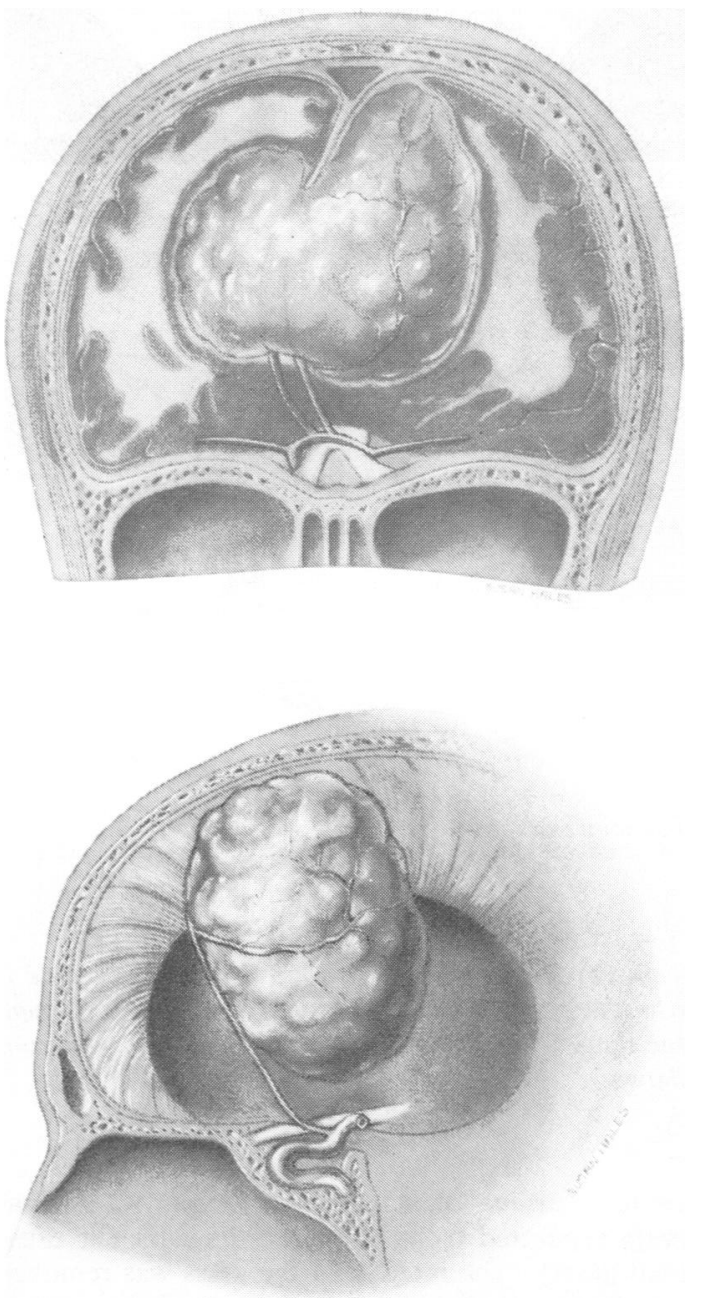

FIGS 4 (top) and 5 (bottom). Case 1. Drawings of meningioma of falx cerebri and neurovascular relationship. carotid artery and the circle of Willis as filling defects in the air, or as direct contrast-filled shadows and, in this way, the relationships of the nerves and the arteries may be worked out before operation. By utilizing such information it is believed that the mechanism of nasal hemianopia has been explained in the three cases now to be described.

\section{CASE 1}

E.P., a 53 year old woman, was admitted to St. Bartholomew's Hospital on 2 November 1962 complaining of urinary incontinence. For 38 years she had been increasingly troubled by hirsutes. She had had one normal pregnancy and had menstruated until the menopause at 48 years. Endocrine function had been investigated in hospital three years before and found normal, though the pituitary fossa was considered to be enlarged, and a diagnosis of pituitary tumour had been made. Since there was then no subjective or objective visual disturbance, further investigation with a view to surgical treatment was not considered. For two years before her latest admission she had suffered from urinary incontinence, mainly but not invariably nocturnal. Over the same period she became forgetful, lethargic, apathetic, and unsteady when walking. After exclusion of the diagnosis of adrenal tumour, she was referred for neurosurgical investigation. There was nothing relevant in the past or family history.

Examination revealed a retarded woman with difficulty of comprehension, slowness of thought, disorientation, and dyscalculia; she was euphoric and lacking in insight. Facial hirsutes was well marked. There was no swelling of the optic discs and the visual acuity was normal; the left visual field showed an inferior quadrantic nasal defect (Fig. 1). There was a left central facial paralysis, a spastic weakness of the right arm, largely proximal, with ataxia and a coarse tremor. In the lower limbs there was spasticity, ataxia, and moderate weakness greater on the right side. There was no demonstrable sensory disturbance, but a grasp reflex on the right with general hyper-reflexia, reduced right abdominal reflexes, and flexor plantar responses. The gait was ataxic on a wide base and Romberg's sign was positive. Skull films revealed that the posterior clinoid processes and dorsum sellae had disappeared and there was a large sphenobregmatic sinus. Carotid angiography revealed a very large left frontoparietal tumour. It displaced the falx cerebri to the right and there was a gross displacement of the left anterior cerebral artery far to the right of the midline (Figs 2 and 3).

A left frontoparietal flap was made and, when the 


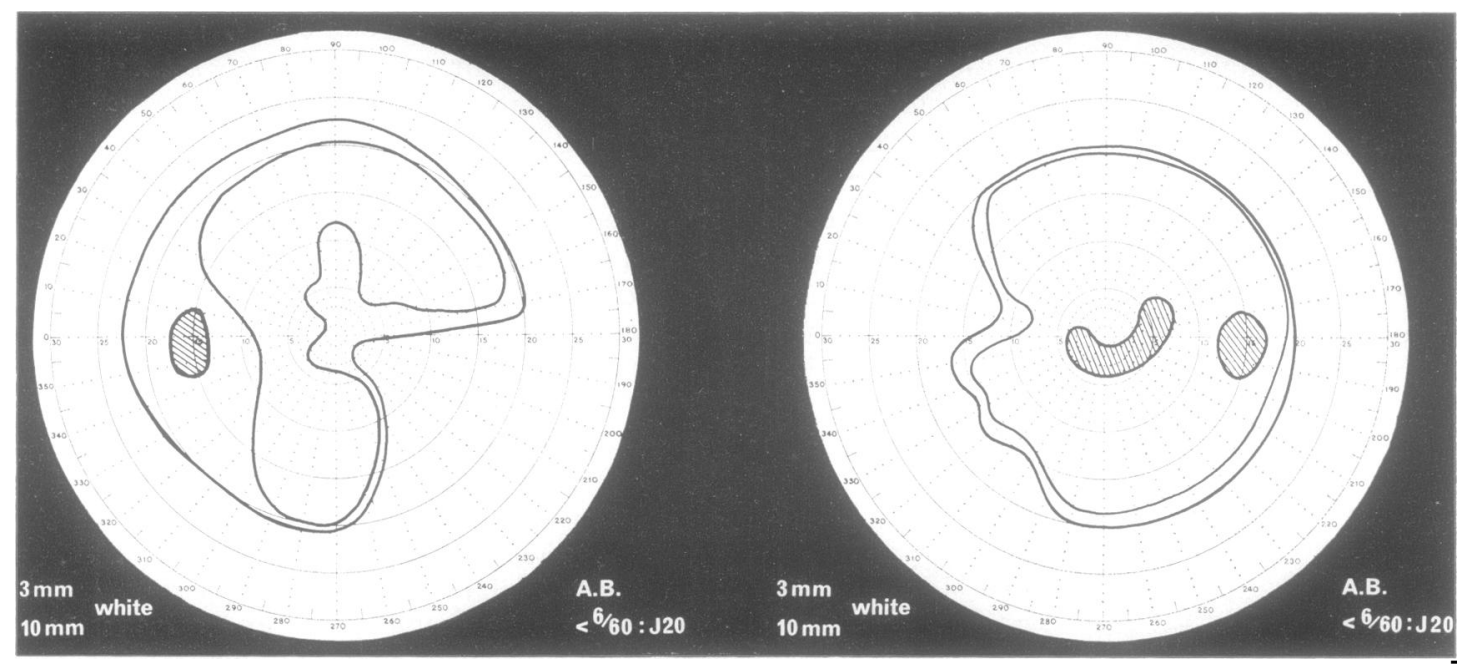

FIG. 6. Case 2. Fields of vision.

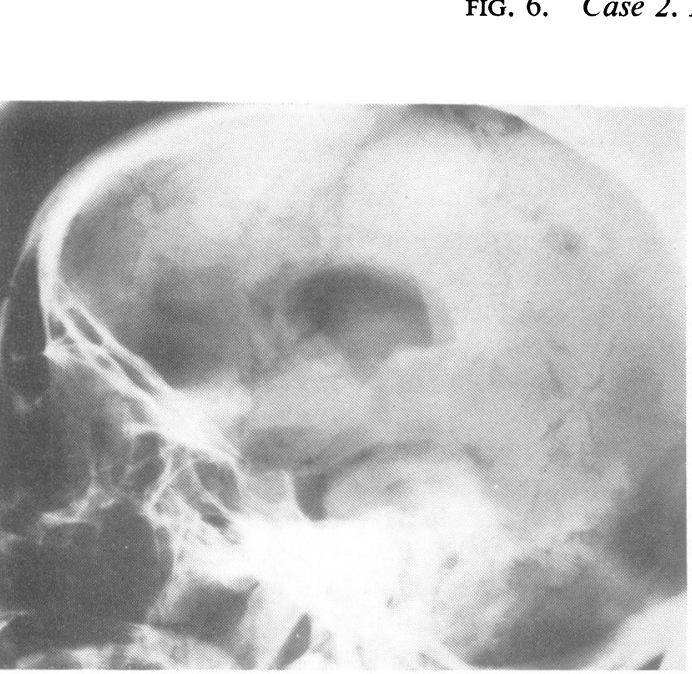

(a)

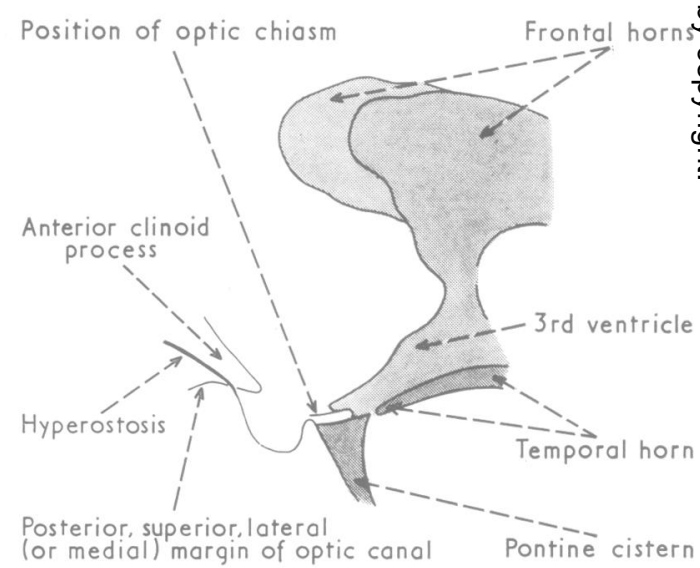

(b)

FIG. 7. Case 2. (a) Pneumoencephalogram, lateral, brow up. (b) Explanatory drawing: the third ventricle is displaced inferiorly and posteriorly and its optic recess marks the position of the chiasma. The commencement of the intracranial course of the optic nerve is shown by the margin of the anterior clinoid process; posterior displacement of the frontal horns of the ventricles is also shown.

tense dura mater had been relaxed by the injection of $40 \mathrm{~g}$ urea intravenously, reflection of the dural flap revealed a walnut-sized tumour attached to the convexity dura mater beneath the skull peripheral to the anterior limb of the bone flap. This was excised and a firm mass was palpated beneath the wide flat convolutions in the anterior part of the exposure. Retraction of the cerebrum from the falx exposed the nodular surface of a globular tumour. This was gently separated from the cerebrum which it excavated deeply. The interior of the mass was removed with cutting diathermy and suction and the capsule folded in upon itself. It separated readily from the superior sagittal sinus and falx cerebri as far as its place of attachment near the free margin of the latter. The falx was incised at this point and a very 
large right-sided mass was seen excavating the right cerebrum. After removal of the interior of this portion of the tumour, the capsule on the right side was separated from the right cerebrum. A large branch of the left anterior cerebral artery entering the capsule was clipped and divided, the right artery being carefully preserved. The capsule was now peeled from its remaining attachments and removed, and the usual closure effected. Both tumours were meningiomata, in part fibroblastic and in part transitional.

Postoperatively, consciousness was not fully regained for 15 days. Then the pupils remained large and poorly reacting and there was a paralysis of upward eye movement. These changes were thought to be due to oedema of the brain-stem which had almost certainly been distorted preoperatively by this very large tumour. The paralysis slowly cleared over a number of weeks and all evidence of frontal lobe deficit disappeared. Nine years postoperatively she remained extremely well from the neurosurgical viewpoint, although after six years she had surgical treatment for a fibrosarcoma of the terminal ileum.

The tumour here did not reach the skull base and the chiasma was not seen. Examination of the carotid angiogram permits placement of the left optic nerve and indicates that it lies in the groove between the stretched left anterior cerebral artery and the medially displaced left internal carotid artery. Thus can be explained the inferior nasal quadrantic defect in the left visual field (Figs 4 and 5), the superior uncrossed fibres in the nerve having been compressed by the anterior cerebral artery.

\section{CASE 2}

A.B., a 53 year old woman, was admitted to the Department of Neurological Surgery of St. Bartholomew's Hospital on 30 December 1968 complaining of failing vision. She stated that during the previous
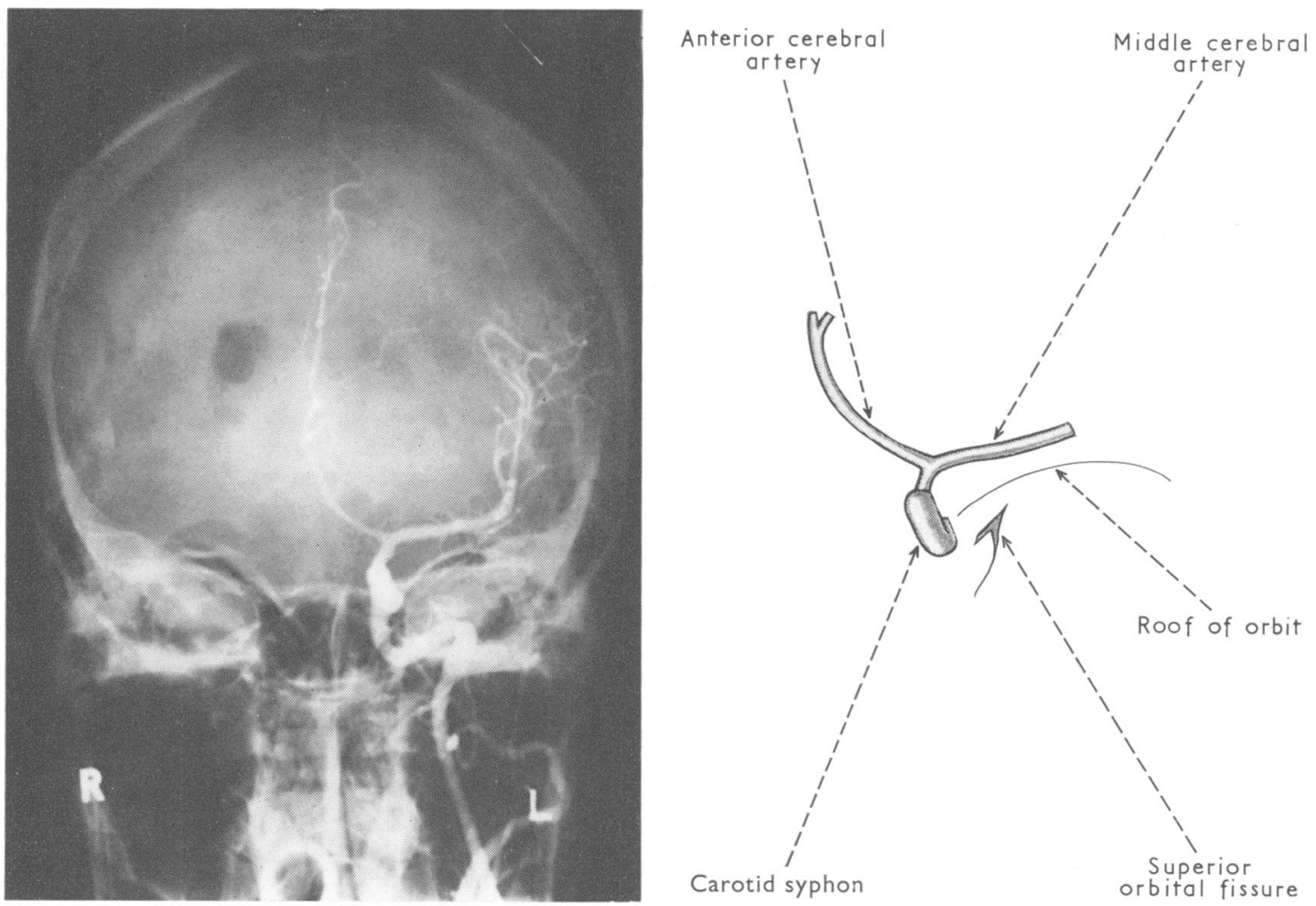

(b)

FIG. 8. Case 2. (a) Left carotid angiogram: A.P. (b) Explanatory drawing: the anterior cerebral artery is tightly stretched inferior and posterior to the tumour. The position of the ophthalmic artery indicates the commencement of the intracranial course of the optic nerve. 


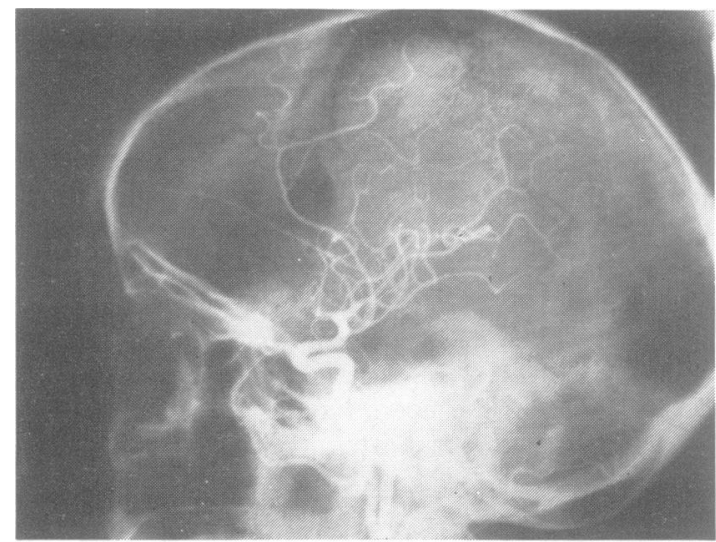

(a)

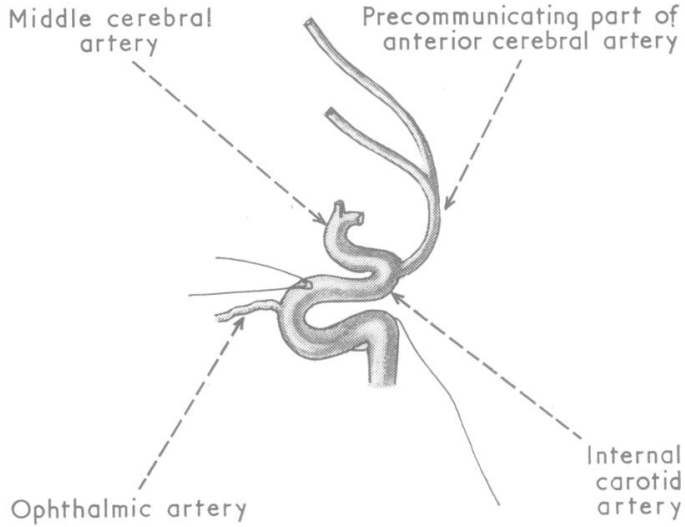

(b)

FIG. 9. Case 2. (a) Left carotid angiogram: lateral. (b) Explanatory drawing: the most displaced branches of the anterior cerebral artery, the carotid syphon and the ophthalmic artery are shown. The ophthalmic artery indicates the site of the optic foramen and the position of the precommunicating part of the anterior cerebral artery indicates downward displacement of the structures in this region.

five months sight had progressively deteriorated in both eyes. Near and distant vision were equally affected and she had become unable to distinguish colours. There had been no associated headache, sickness or diplopia, nor any symptoms of endocrine disturbance. Indeed, the only other symptom was a reduction of the sense of smell. In the past history a point of significance was the occurrence of two generalized epileptic attacks two and a half years earlier. No abnormality was found at the time apart from some left temporal paroxysmal features at electroencephalography. With anti-convulsant medication there was no recurrence of attacks.

Examination revealed a well-orientated, heavily featured, obese woman with no abnormality on general examination. The abnormalities on neurological examination were a bilateral anosmia, some pallor of the left optic disc, and a marked reduction of visual acuity-VAL less than 6/60ths and $\mathrm{J} 20$; VAR less than 6/60ths and $J 18$ (corrected). The visual fields showed an inferior nasal quadrantic defect on the left and a less well-defined nasal defect on the right ( $10 \mathrm{~mm}$ test object); with a $3 \mathrm{~mm}$ test object the left-sided quadrantic defect was seen to involve central vision and there was some diminution of the temporal field, while on the right a pericentral scotoma was added to the nasal defect (Fig. 6). The only other neurological abnormality was a possible left central facial paresis. Lumbar puncture revealed that the cerebrospinal fluid (CSF) had a pressure of $200 \mathrm{~mm} \mathrm{CSF}$ and a protein content of $116 \mathrm{mg} / 100 \mathrm{ml}$.
Plain skull films showed an area of sclerosis of the skull base in the posterior ethmoidal region, and pneumoencephalography a bilateral subfrontal mass larger on the left side (Fig. 7). Bilateral carotid angiography confirmed that these appearances sug gested the presence of an olfactory groove meningioma (Figs 8 and 9).

A right frontal craniotomy was effected, the tumour palpated through the frontal lobe with a cannula, and the right frontal horn tapped of a few $\mathrm{ml}$. CSF. After reflection of the dural flap and elevation of the frontal lobe, a large lobulated tumour was revealed. A small (37 g) frontal lobectomy was made and piecemeal removal of the interior of the tumour commenced. This was achieved in the case of both the left and right portions of the mass. Its attachment to the cranial floor posterior to the cribriform plates was now separated and, after splitting the falx cerebri to improve the exposure, the capsule was withdrawn from beneath both frontal lobes to expose the suprasellar portion. After clipping one branch of the right anterior cerebral artery, separation was effected here and the capsule removed. A distinct tumour $1 \mathrm{~cm}$ in diameter attached to the dura mater over the left orbital roof was also excised. The enostosis on the cranial floor was heated with coagulating diathermy and covered with a pericranial graft and the wound closed in the usual manner. Histologically, the tumours were meningiomata of syncitial type.

The relationship of the tumour to the optic nerves 

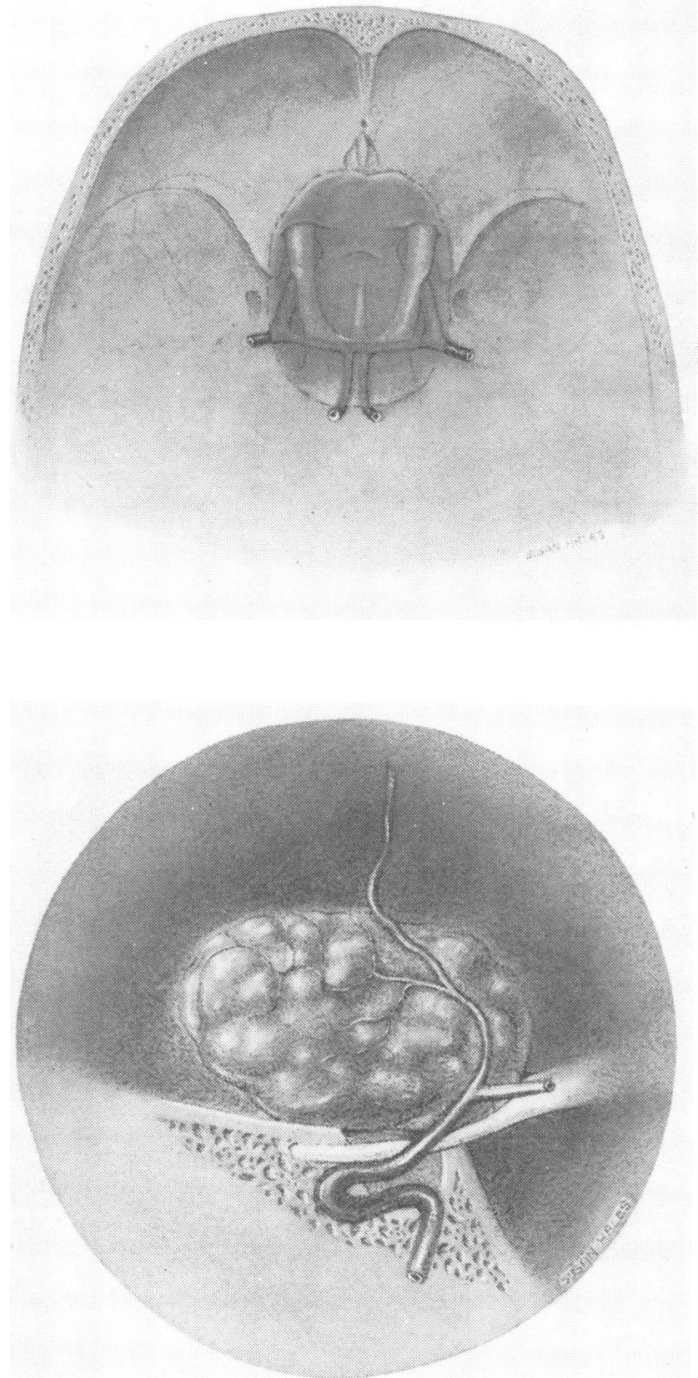

FIGS 10 (top) and 11 (bottom). Case 2. Drawings of olfactory groove meningioma and neurovascular relationships.

and chiasma was of particular interest (Figs 10 and 11). The chiasma was postfixed and the hyphophyseal stalk was seen emerging from beneath it and passing anteriorly to penetrate the sellar diaphragm. The optic nerves had been arched inferiorly by the tumour and also displaced laterally on to the internal carotid arteries whose medial margins could be seen medial to the nerves anteriorly. Posteriorly, each internal carotid artery was tethered medially by the stretched anterior cerebral arteries and had notched the lateral aspects of both optic nerves. Postoperative recovery was rapid with full restoration of visual acuity, but a persistent inferior nasal quadrantic field defect on the left.

Study of the pneumoencephalogram and the carotid angiogram here reveals the relationship between optic nerves and internal carotid arteries seen at operation. Compression of the lateral portions of the nerves by the internal carotid arteries is believed to be the explanation of the binasal hemianopia.

\section{CASE 3}

J.Z., a 50 year old man, was admitted to St. Mary's Hospital, London, under the care of Dr. Roger Bannister on 26 October 1968, complaining of blurred vision. For five weeks vision in his left eye had progressively deteriorated and for two weeks right vision had been involved. There were no other symptoms, in particular none of headache or endocrine disturbance. There was nothing significant in the past history.

He was a fit-looking man without clinical evidence of endocrine abnormality. The abnormal physical signs were confined to visual function, the acuity on the right being $6 / 18$ and on the left $6 / 36$. There was pallor of the optic discs, greater on the left, and visual field examination showed a heteronymous hemianopia, the inferior nasal quadrants being those affected (Fig. 12). Investigation showed normal thyroid function but reduced 24 hour urinary excretion of ketosteroids, and a plasma cortisol at the lower level of normal. Skull films showed a greatly enlarged sella turcica, and pneumoencephalography a defect in the anterior third ventricle (Fig. 13). Bilateral carotid angiography revealed lateral displacement of the termination of the internal carotid arteries and elevation of the first part of the anterior cerebral arteries-the right being hypoplastic (Figs 14 and 15).

Operation was carried out by Mr. L. Walsh. Through a right frontal exposure it was seen that the right optic nerve was elevated and displaced laterally, with the tumour and internal carotid artery lying beneath it. An intracapsular excision of the tumour (a chromophobe adenoma) was effected and the chiasma and right optic nerve satisfactorily decompressed. The posterior end of the left nerve was seen and appeared normal. Closure was then effected and the patient subsequently received a course of irradiation to the sellar region. He made excellent progress and on examination one year later his visual acuity was normal, though bilateral inferior 


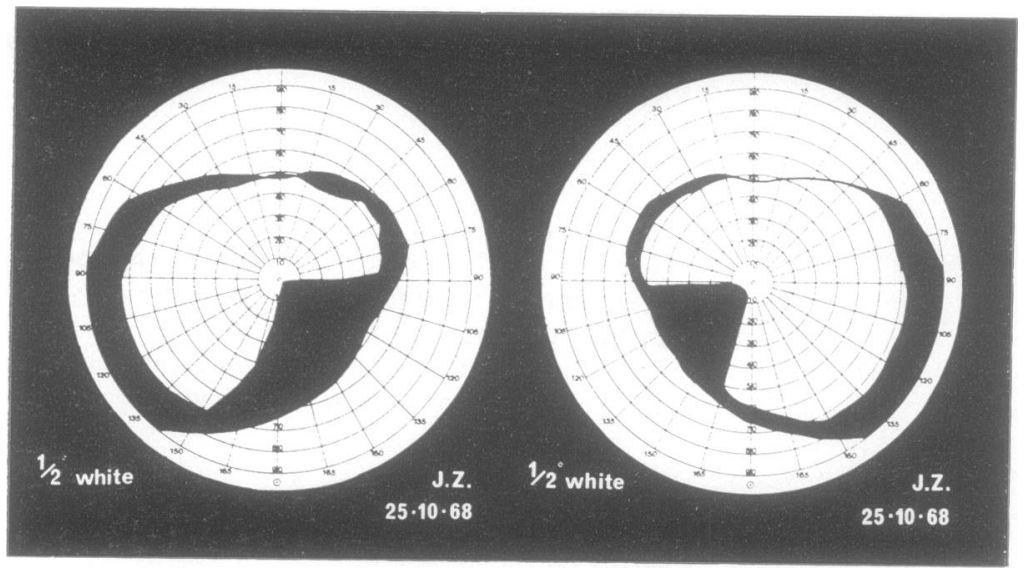

FIG. 12. Case 3. Fields of vision.

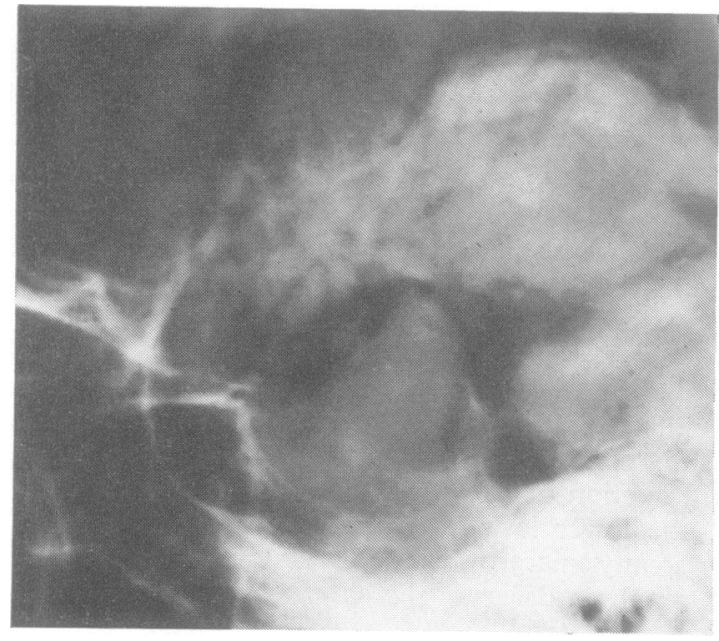

(a)

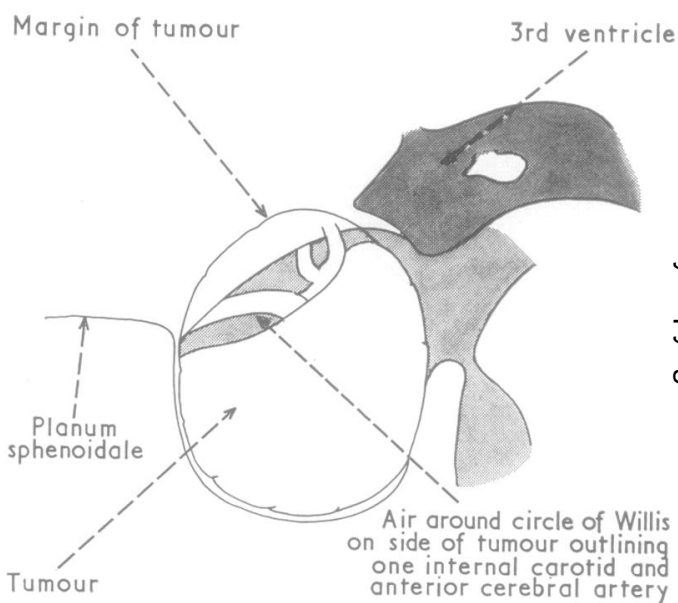

(b)

FIG. 13. Case 3. (a) Pneumoencephalogram, lateral, brow up. (b) Explanatory drawing: the anterior end of the third ventricle, indented and displaced, shows the position of the optic chiasma. The suprasellar portion of the tumour is outlined by air which also reveals the shadows of parts of the circle of Willis lying on its surface.

nasal quadrantic defects were still present but reduced.

Study of the pneumogram and the carotid angiogram here shows that the right optic nerve is crossed on its lateral aspect by the stretched anterior cerebral artery arching over the tumour (Figs 16 and 17). It is believed that this explains the right inferior nasal quadrantic field defect and that there was a similar explanation for the same type of field defect on the left side.

\section{DISCUSSION}

As has been described, compression of the optic nerves, tracts and chiasma by the Willisian vessels is a well-documented postmortem finding. It may result from aneurysms or sclerotic changes in the internal carotid arteries or displacement of the nerves against vessels, or of the vessels against the nerves. As a result of such displacements, the vessels have been shown to cut deep 


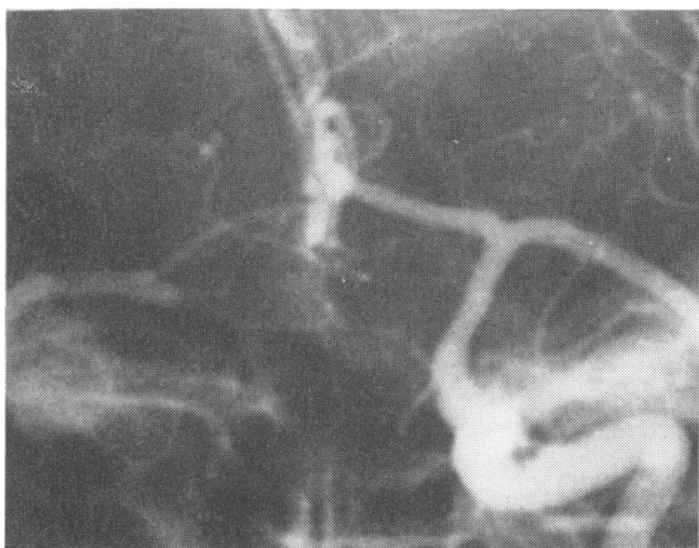

(a)

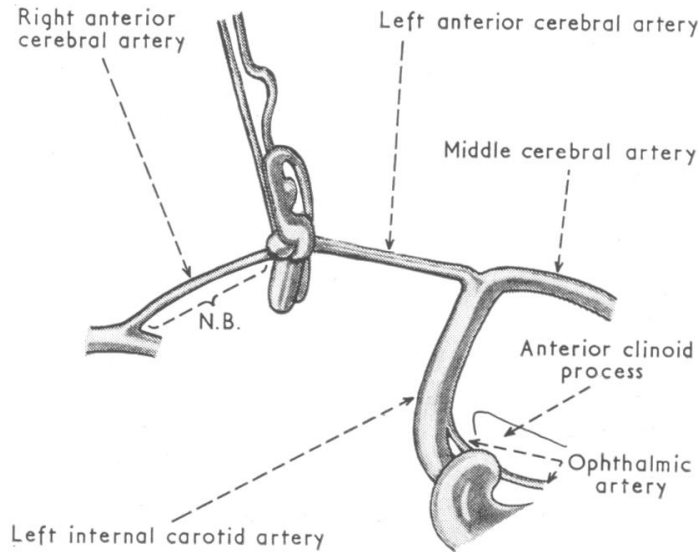

(b)

FIG. 14. Case 3. (a) Left carotid angiogram: A.P. (b) Explanatory drawing: the precommunicating parts of both anterior cerebral arteries are stretched by the tumour beneath them.

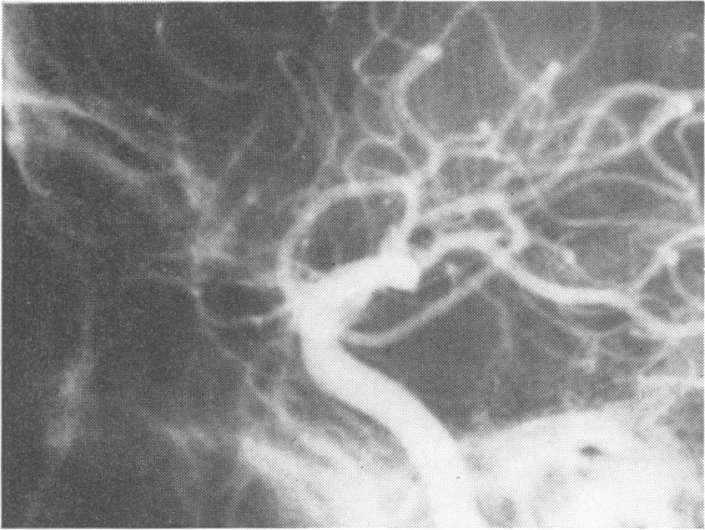

(a)

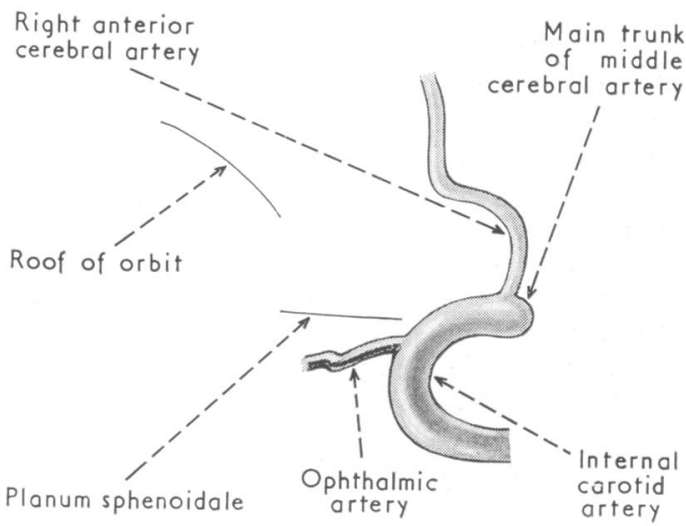

(b)

FIG. 15. Case 3. (a) Right carotid angiogram: lateral. (b) Explanatory drawing: the course of the anterior cerebral artery displaced superiorly and posteriorly is indicated-it is but faintly outlined in the angiogram. The osseous portion of the ophthalmic artery places the optic canal on the film.

grooves in the nervous structures. Neurosurgeons have at intervals remarked upon such groovings observed at operation and occasioned by the anterior cerebral artery. For the most part they have not been related to visual field defects which may have existed. When the fields have been charted and preoperative investigation carried out to display the detailed relationships of nerves to blood vessels and tumour, demonstration of the vascular cause of certain field defects is possible. This has been done in the three patients described above and the possibility of binasal hemianopia being the result of a single lesion, and thus a true hemianopia has been demonstrated. In case 1 a great medial displacement of one anterior cerebral artery by an 

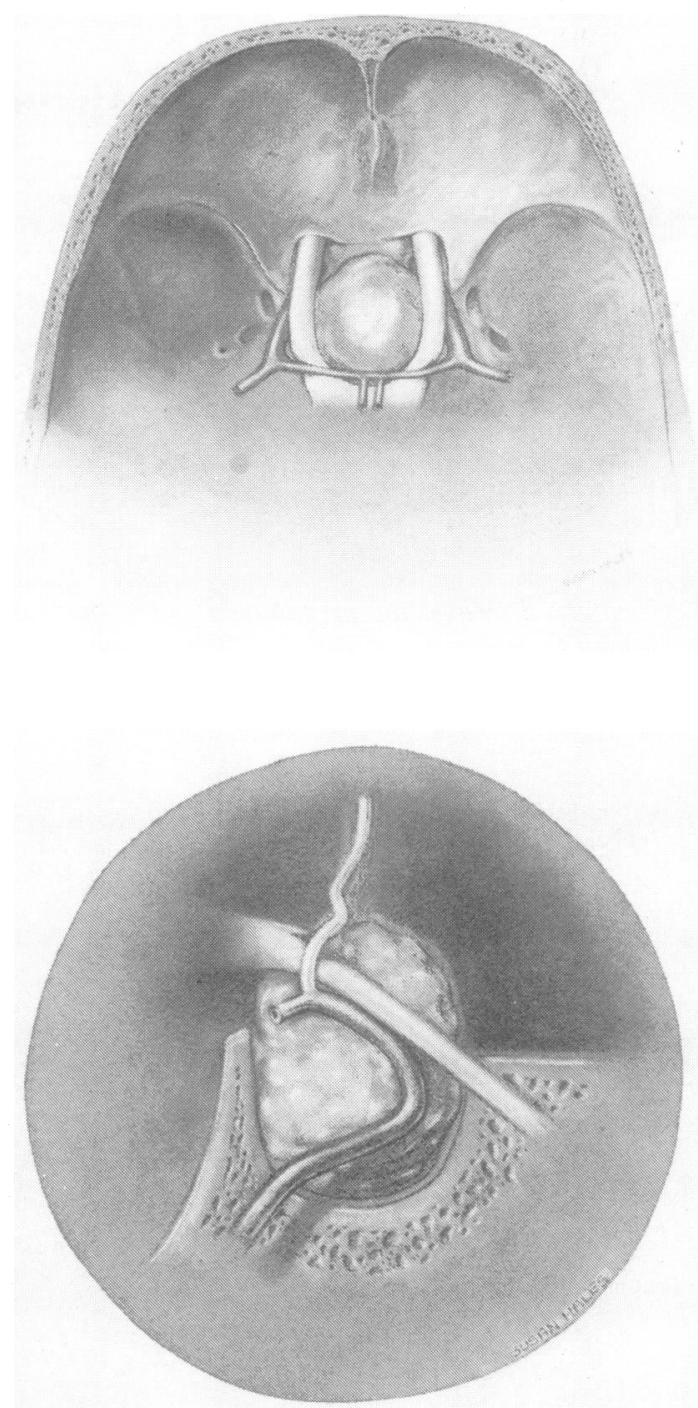

FIGS 16 (top) and 17 (bottom). Case 3. Drawings of chromophobe pituitary adenoma and neurovascular relationships.

enormous falx meningioma caused it to groove the superolateral aspect of the related optic nerve and produce an inferior quadrantic nasal defect in the field of the ipsilateral eye. In case 2 an olfactory groove meningioma displaced the optic nerves inferiorly and laterally-the postfixation of the chiasma permitting this displace- ment without the development of a bitemporal hemianopia. The internal carotid arteries were drawn medially by the stretched anterior cerebral vessels and the lateral fibres of the optic nerves grooved by them with the production of a binasal hemianopia. In case 3 the radiological findings again suggest lateral displacement of the optic nerves against the stretched anterior cerebral arteries with grooving of their lateral aspects. Possibly an unusually intimate relationship between the anterior cerebral arteries and the optic nerves caused arterial compression of them before the degree of displacement necessary to produce a bitemporal hemianopia had occurred.

The common type of heteronymous hemianopia is a bitemporal one; the binasal one is rare and may be produced by the mechanism described. The relative insensitivity of the lateral fibres of the optic nerves and chiasma to the presence of a suprasellar mass suggests that in some respects they differ from the medial fibres. Observations, which will be discussed in a subsequent paper, suggest that this difference lies in the more rapid development of internal tension $\frac{\rho}{2}$ 을 in the medial fibres after displacement thane occurs in the lateral fibres. However, if the nerve $O$ is brought into contact with one of the Willisiano 음 vessels lying on its lateral aspect, the lax laterat fibres are compressed between the artery and the $\overrightarrow{0}$ more tense medial fibres and a sharply localized $\vec{\omega}$ pulsatile vascular compression results; this distorts nerve fibres acutely and occasions disturbance of their function. Conditions such as a postfixed chiasma and optic nerves which are readily displaceable or an existing intimate relationship between nerve and artery will make the development of such vascular compression the more likely. Absolute proof of this mechanism of production of a binasal hemianopia would necessitate the demonstration of the neurovascular relationships with appropriate grooving of the nerve or chiasma at operation or necropsy. It is believed, however, that the evidence presented here goes some way to demonstrate a cause and possibly the only common cause of binasal hemianopia.

The authors would like to express their gratitude to Dr. Roger Bannister and Mr. L. Walsh for permission to examine the records of case 3 and publish an account of the case. They are also much indebted 
to the Department of Medical Illustration of the Hospital for the preparation of the photographic plates and to Miss Susan Hales for her careful drawings.

\section{REFERENCES}

Balado, M., and Malbran, J. (1933a). Contribución a la estructura del quiasma óptico humano (hemianopsia binasal; estudio anátomo-clínico). Semana Médica (Buenos Aires), 2, 797-807.

Balado, M., and Malbran, J. (1933b). Compresión y sección del quiasma por las arterias del polígono de Willis. Archives Argentinos Neurolinos, 9, 126-133.

Bartels, M. (1906). Ueber Plattenepithelgeschwülste der Hypophysengegend (des Infundibulums). Zeitschrift für Augenheilkunde, 16, 407-438, 530-560.

Bull, J. W. D. (1956). The normal variations in the position of the optic recess of the third ventricle. Acta Radiological (Diagnosis), 46, 72-80.

Cushing, H., and Walker, C. B. (1912). Binasal hemianopsia. Archives of Ophthalmology, 41, 559-598.

Dilenge, D. (1955). Anatomie radiologique de la citerne optochiasmatique. Neurochirurgie, 1, 257-267.

Duke-Elder, Sir S. (ed.) (1971). Neuro-ophthalmology. System of Ophthalmology. Vol. 12, pp. 292-293. Kimpton: London.

Fay, T., and Grant, F. C. (1923). Lesions of the optic chiasm and tracts with relation to the adjacent vascular structures. Archives of Neurology and Psychiatry, 9, 739-750.

Gado, M., and Bull, J. W. D. (1971). The carotid angiogram in suprasellar masses. Neuroradiology, 2, 136-153.

Hirsch, O. (1921). Über Augensymptome bei Hypophysentumoren und ähnlichen Krankheitsbildern. Zeitschrift fiir Augenheilkunde, 45, 294-309.

Knapp, H. (1873). Hemiopic and sector-like defects in the field of vision. Archives of Scientific and Practical Medicines, 1, 293-310.

Liliequist, B. (1959). The subarachnoid cisterns: an anatomic and roentgenologic study. Acta Radiologica (Diagnosis), Suppl. 185.

Rucker, C. W., and Kernohan, J. W. (1954). Notching of the optic chiasm by overlying arteries in pituitary tumors. Archives of Ophthalmology, 51, 161-170.

Scott, G. I. (ed.) (1957). The optic nerve. In Traquair's Clinical Perimetry, p. 208. Kimpton: London.

Schneider, R. C., Kriss, F. C., and Falls, H. F. (1970). Prechiasmal infarction associated with intrachiasmal and suprasellar tumors. Journal of Neurosurgery, 32, 197-208.

Smith, G. Elliot (1905). A note on nervous lesions produced mechanically by atheromatous arteries. Review of Neurology and Psychiatry, 3, 182-184.

Türck, L. (1852). Über Compression und Ursprung des Sehnerven. Zeitschrift der kais. kön. Gesellschaft der Aerzte zu Wien, 8, II, 299-304.

Uhthoff, W. (1923). Ueber einen Fall von binasaler Hemianopsie. Klinische Monatsblätter für Augenheilkunde, 70, 138-140. 